\title{
Color Psychology in Marketing
}

\author{
DR.SAJID REHMAN KHATTAK \\ Assistant Professor, The University of Agriculture, Peshawar \\ sajidktk99@yahoo.com \\ HAIDER ALI \\ PhD Scholar, Qurtuba University, Peshawar \\ haider.ale@gmail.com \\ YASIR KHAN \\ PhD Scholar, Qurtuba University, Peshawar \\ haider.ale@gmail.com \\ MUKHARIF SHAH \\ Lecturer, Institute of Business Studies and Leadership \\ Abdul Wali Khan University Mardan
}

\begin{abstract}
The purpose of this research was to review the psychology of colors in marketing. People make their minds about product or people within 90 seconds. About 62 to $90 \%$ of a product or people assessment is based on colors alone. Thus, a color is not only using to differentiate your product from your competitors, but it also affects the moods and feelings of the individual buyers, thus colors make attitude towards a certain product. Human feelings and moods are changeable overtime; thus, every marketing managers should know the importance of colors and make their products or packaging accordingly. This study evaluates the literature linking to color psychology. The study found that colors play an important role in marketing. Managers should give immense attention to their brands and products colors in order to attract a large number of customers. Limitations and future research agenda are presented.
\end{abstract}

Key Words: Color, Psychology, Marketing

\section{Introduction}

Our senses play crucial and fundamental role in understanding of the surrounding world. Among five senses the sense of sight is most critical and important. Indeed, it is our senses that help us in selecting different brands of different companies. Color selection is of immense importance in marketing and branding. Color is considered a powerful medium through which we view the world. It is revealed in a research study that people make their minds about a people or a product within 90 seconds. It is also revealed that 62 to 90 percent of a product consideration is based on colors alone (Gopikrshna \& Kumar, 2015). Colors are the most crucial factor that influences our perception about something's. Its impact is visible in every part of our daily lives and it is considered an important element in consumer behavior. 
Color is caused by the interaction of spectrum of light with the spectral sensitivity of the light receptor in the eyes. When light interact with this receptor eyes it split to six distinct colors. Light sources emit light of different wavelength. As a result of difference in wavelength, different light creates new colors and we perceive a combination of different colors. In a nut shell, the color of an object generally depends on two cases i.e. physical object in their environment and the second one is how I and brain perceive that object. Psychologists divide color into the following main section;

- cool color which comprise blue and green

- warm color which is consists of red and yellow

- neutral color which includes white, black and gray

Color is essential element of marketing in corporate communication. Selection of color enhances or decrease productivity of any product. Color induces moods and emotions of the customers and it significantly influences perceptions and behaviors of the consumers. Color also helps companies to distinguish its position from other competitors. Often it is seen that within a given market different companies choose different colors that will differentiate them from the competitors. For example, in mobile market Verizon owns red T-Mobile, owns pink and AT \& A owns blue. In the domain of marketing color is an important element in promoting different products, providing different services, packages, displays and logos of different products. Color is an important sign for creating and sustaining identity of different products in the competitive markets. It attracts consumers' perceptions for differentiating different brands. Palmer and Scheoss, (2010) cited a theory about color preferences which is known is ecological valence theory. This theory states that color preferences result from the individual emotional reactions towards the color related object. People prefer such colors which are directly associated with objects they prefer.

Color is considered by customers is one of the first primary factor which influences their shopping behavior and product selection. It is also revealed in a research study that choice of color selection is largely depend on demographic variables of the consumers like age, socio economic level, gender, race, culture, and ethnicity. Understanding and meaning of color is changing overtime. The knowledge and awareness of customer color choices enables marketers to identify and offer the most suitable color of the product. Color is also used to attract and create a purchasing intention in retail stores. Customers have different inclination towards different color preferences in order to select different categories of products. Customers' choice for a color might not match with color of the product which they believe suitable. It means that colors are not perceived independently from context and therefore companies cannot manufacture their product color choice which is based on the choice of consumers (Plieninger, Dijks, Oteros-Rozas, \& Bieling, 2013).

Color is a critical element in logo design and brand personality. It can be considered a crucial marketing variable for creating and managing images of the standard of the products. It is believed that color can function not only as in instant identifier of its brands but it also connotes the price and quality of the product. Thus, selection of right color for a product promotes and recognizes product importance and utility. On the other hand, when a wrong color of a product is selected it may hamper any communication between a company and its market. The process of color selection is mainly depending on average life of the product and price level of the product. 
For example, when high priced and long lives of product are involved people are generally paying more attention to color in their choices. On the other hand, consumers are more flexible in their choices when low prices and short life of product is involved. In marketing, every color has a different feel for consumers and various other associations. A company chooses a color or a combination of different colors to distinguish its product from other competitors. Colors evoke certain feeling and emotion towards a product and it is an important sign for a company to represent its products effectively. Selection of different colors motivate to specific types of shoppers and personality. Table 1 show how different colors appeals to different shoppers and personalities.

\subsection{Color Controversy}

There is no unanimity among scholars regarding the role of color and human personality. Conventional psychologists reject the role of color in influencing human personality. A modern psychologists' stresses that color play significant role in determining our personality. However, the role of color is visible in following field of our life:

\subsubsection{Color and Health}

The role of color is being considered an important one in health for decades. Ancient Egyptian doctors healed their patients while bathing them in color of light. This pattern has re-rise as a branch of new age prescription. Different colors have been linked to heal different ailments. For example, red color has been considered to energize the liver, purple color lower blood pressure, orange color is considered to strengthen lungs and increases calcium metabolism. Green color plays role in sympathetic nerves system and yellow color is effective an energizing the alimentary tract.

\subsubsection{Color and Culture}

Color is also entirely dependent on culture and religion. Studies found that blue color was the most acceptable color in almost all culture (Singh, 2006; Wiegersma \& Vander Elst, 1988). In India, the most sacred color for Hindu is orange. On the other hand, culture like Ndembo of Zambia do not considered orange as a color. Until the introduction of white color by Christian Pops for wedding, Celts considered green as a sacred color. Muslims also consider green as a sacred color. Inuit communities preferred white color. In Melanesia, the combination of red and white was used for ritual decorations (Plieninger, Dijks, OterosRozas, \& Bieling, 2013). The detail of each color and its meanings in different countries and cultures are reported in appendix.

\subsubsection{Color and Emotions}

Peoples are affected and attached with different colors emotionally. The association between colors and emotions was studied by Boyatzis, \& Varghese, (1994) and found that brown, black and red as sad colors, and blue, orange and yellow as happy colors. They also argued that these emotions were similar across age groups. Atmospherics elements like aromas, sizes, clamors, shapes and hues could pass on messages make consideration and make shape emotions that may upgrade buy likelihood (Singh, 2006; Kotler, 1973). Various studies link color and consumer emotion and perception. Hamphill (1996) found that colors like blue, white, red and pink create positive reactions in people such as happiness and excitement, while colors like brown and black react oppositely. Labrecque and Milne, (2012) argued that brand's uses red and orange colors for the purpose to conveys more excitement as compared to other cooler colors like blue. Similarly, Dijkstra et al. (2008) found that hospital rooms having blue walls are less stressful than those having orange walls which are more 
stimulating as compared to those rooms having white walls. Table 4 in appendix shows colors and feelings in detail.

\subsubsection{Color and Gender}

Genders perceptions regarding colors vary. Men are more tolerant of black, white and gray as compared to women, and women more frequently reacted to red and blue combinations (Khouw, 2002). They also argued that adults also preferred the combination of red and blue. These historical findings suggest that gender perception regarding color differ.

\section{Application of Color in Marketing}

Hues have all the earmarks of being confrontational. Several speculations or rumors have given rise due to the lack of conclusive scientific studies relating to colors. Some advances in the research have been observed regarding this phenomenon but it came from companies in the color consultation industry. Although, the nature of their research is not experimental, their results mostly depend on general agreement among marketers (Singh, 2006). Some applications of color in marketing are reported below;

\subsection{Colors and Restaurants}

Fast-food restaurants preferred red color because it affects our metabolism. Fast-food moguls also used yellow color to attract customers' attention, increase appetite and motivate them to eat. To generate high sales this is considered the best way for fast-food restaurants. On the other hand, formal restaurants use blue color to relax and calm their customers. Formal restaurants use such type of strategy to improve their sales. Kido (2003) linked blue to calm state. They also argued that excessive use of blue color can be appetite suppressant.

\subsection{Colors and Waiting Time}

Colors influence perception regarding passage of time. Under a red-light object seem heavier and longer and time seems to pass slowly. On the other side, under a blue light objects seem lighter and smaller and time seems to pass very quickly. Casinos take advantage from this strategy- by using red lighting to excite their customers and make their feeling that they are not wasting more time in casinos.

\subsection{Colors and Brands}

Colors evoke brands. Whether it is Cadburys purple, Coca-Cola's red, Heineken's green and Shell's yellow, all these companies have different color values to different customers. Tutssel (2000) argued that color attached strong emotional feeling that prompt an immediate response to packaging than either the written work. As we discuss earlier, the meanings of colors changes with every culture. Product having a gray packaging are considered cheap goods in China and Japan while in US it is considered a high-quality goods; likely in US cheap goods are labeled or pack in purple color and in Asian context expensive goods are labeled or pack in purple color. Thus, companies pay more attention to brands color to attract a larger segment (Grossman \& Wisenblit, 1999).

\section{Conclusion}

Hues are disputable. A few therapists trust that human reactions to colors are steady, along these lines pertinent to everybody. While some psychologists are disagreeing with this notion. They believe that colors preferences vary from individual to individual and from culture to culture, and between gender and age group. Marketing managers should aware and select the most preferred colors to gain competitive advantage. Walls colors of store and product packaging can attract customers' attention and increase their sales drastically. Before launching a new product, managers should conduct a research regarding colors of the 
product because wrong or inappropriate color will generate negative image in the minds of customers about the product and or company. Global managers should be aware of different colors meanings in different cultures and divide market in multi-segment to boost sales. Now a day's dining out is use for social gathering than eating (Kulman, 2001). People frequency to visits restaurants will increase number of restaurants. Owners differentiate their restaurant from the crowd through attracting customers and to increase profitability. Research shows that appropriate use of walls and carpets colors will increase food sales. In short, marketing managers should give careful attention to their products colors in order to gain a large market share through a huge sale.

\section{Future Research Direction}

The purpose of this research was to study the psychology of colors in marketing. The current research just reviews past literature about the impact of color on marketing. Future research is needed to explore this matter in detail by conducting an experimental research or by using survey questionnaire to quantify the results of the study. Future research should compare different brands based on their colors by taking Pakistani sample.

\section{References}

Boyatzis, C. J., \& Varghese, R. (1994). Children's emotional associations with colors. The Journal of genetic psychology, 155(1), 77-85.

Dijkstra, K., Pieterse, M. E., \& Pruyn, A. T. H. (2008). Individual differences in reactions towards color in simulated healthcare environments: The role of stimulus screening ability. Journal of Environmental Psychology, 28(3), 268-277.

Gopikrishna, R., \& Kumar, M. (2015). A Conceptual Study on Psychology of Colour in Marketing and Branding. International Journal of Economic Research, 12(2).

Hemphill, M. (1996). A note on adults' color-emotion associations. The Journal of genetic psychology, 157(3), 275-280.

Khouw, N. (2002). The meaning of color for gender, Colors Matters-Research.

Kido, Y. (2003). Anti-miscegenation and Asian Americans. Historical Review, 108(5).

Kotler, P. (1973). Atmospherics as a marketing tool. Journal of retailing,49(4), 48-64.

Kulman, L. (2001). In today's restaurants, color my sushi beautiful. US News \& World Report, 130(2), 56.

Labrecque, L. I., \& Milne, G. R. (2012). Exciting red and competent blue: the importance of color in marketing. Journal of the Academy of Marketing Science, 40(5), 711-727.

Palmer, S. E., \& Schloss, K. B. (2010). An ecological valence theory of human color preference. Proceedings of the National Academy of Sciences,107(19), 8877-8882.

Plieninger, T., Dijks, S., Oteros-Rozas, E., \& Bieling, C. (2013). Assessing, mapping, and quantifying cultural ecosystem services at community level.Land use policy, 33, 118-129.

Priluck Grossman, R., \& Wisenblit, J. Z. (1999). What we know about consumers' color choices. Journal of marketing practice: Applied marketing science, 5(3), 78-88.

Singh, S. (2006). Impact of color on marketing. Management decision, 44(6), 783-789.

Tutssel, G. (2000). But you can judge a brand by its color. Brand Strategy, November, 8-9.

Wiegersma, S., \& Van der Elst, G. (1988). Blue Phenomenon: Spontaneity or Preference? Perceptual and Motor Skills, 66(1), 308-310. 


\section{Appendix}

Table 1: How Colors Attract Specific Shoppers

Types of Shopper Cocation Color

Impulse buyers $\quad$ Fast food, outlet malls, Orange, royal blue, black, red

Clearance sales

\begin{tabular}{|c|c|c|}
\hline $\begin{array}{l}\text { Buyers on a } \\
\text { budget }\end{array}$ & $\begin{array}{l}\text { Banks, larger department } \\
\text { store }\end{array}$ & Navy blue, teat \\
\hline $\begin{array}{l}\text { Traditional } \\
\text { buyers }\end{array}$ & Clothing stores & Pink, rose, sky blue \\
\hline
\end{tabular}

Source: Lam, Shun, and Campbell, 2013

Table 2

Introducing color groups and their application

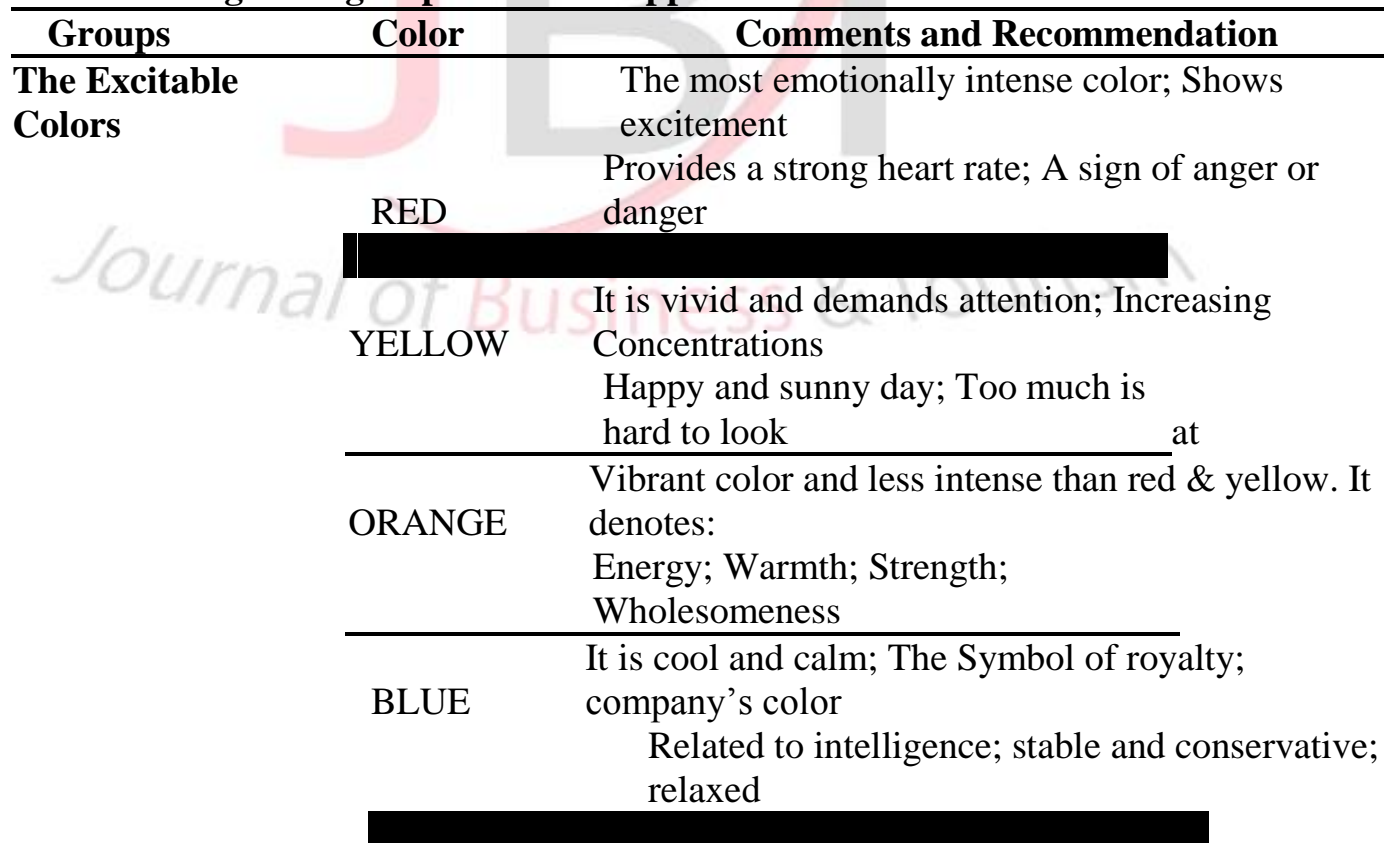

Symbolizes nature, life, renewable, \& environment; The Calming Colors GREEN indicate

wealth Calming and relaxing; can also mean greed, jealousy or envy

PINK Romantic and attractive; cheerful and playful; 


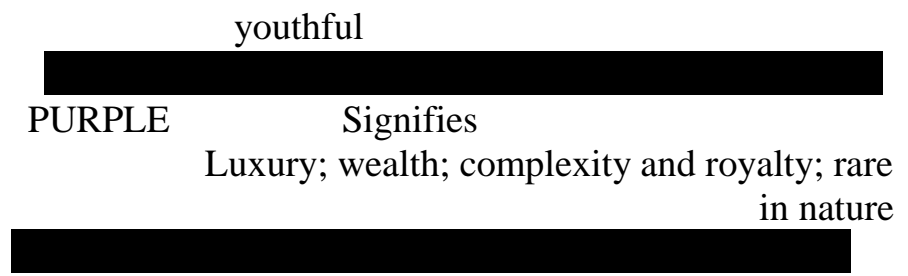

Represents power and authority; serious and BLACK conservative The cryptic and bad; classy

\begin{tabular}{|c|c|c|}
\hline \multirow{6}{*}{ The Neutral Colors } & BLACK & $\begin{array}{l}\text { Represents power and authority; serious and } \\
\text { conservative } \\
\text { The cryptic and bad; classy }\end{array}$ \\
\hline & & the color of purity; conveys innocence $\&$ \\
\hline & WHITE & cleanliness \\
\hline & BROWN & color of earth \& Implies \\
\hline & & $\begin{array}{l}\text { Wholesomeness; sable \& material; } \\
\text { unhappy or eager }\end{array}$ \\
\hline & GRAY & $\begin{array}{l}\text { conservative and formal; moody and balance; } \\
\text { unexciting }\end{array}$ \\
\hline
\end{tabular}

Source: Nezhad \& Kavehnezhad, 2013

Table 3

The meanings of colors in major countries Colors Countries Meanings of Colors

RED

China color of celebration and happiness; long life and vitality

Pakistan Japan shows love and beauty; fertility and purity; power and wealth danger and anger; life

Thailand Sunday's

Russia color

Australia related to communism; used in marriage ceremony

PINK color of earth and land; ceremonial color

\begin{tabular}{lc}
\hline Eastern feminine & \\
Japan & very good suitable for both male \\
Thailand & Tuesday's color \\
Korea & Trust \\
Western & love and romantic - for women \\
Europe & baby girls - feminine color \\
\hline & \\
Western & items cost effective and cheap \\
Eastern & happiness; spirituality \\
Thailand & Thursday's color \\
\hline
\end{tabular}




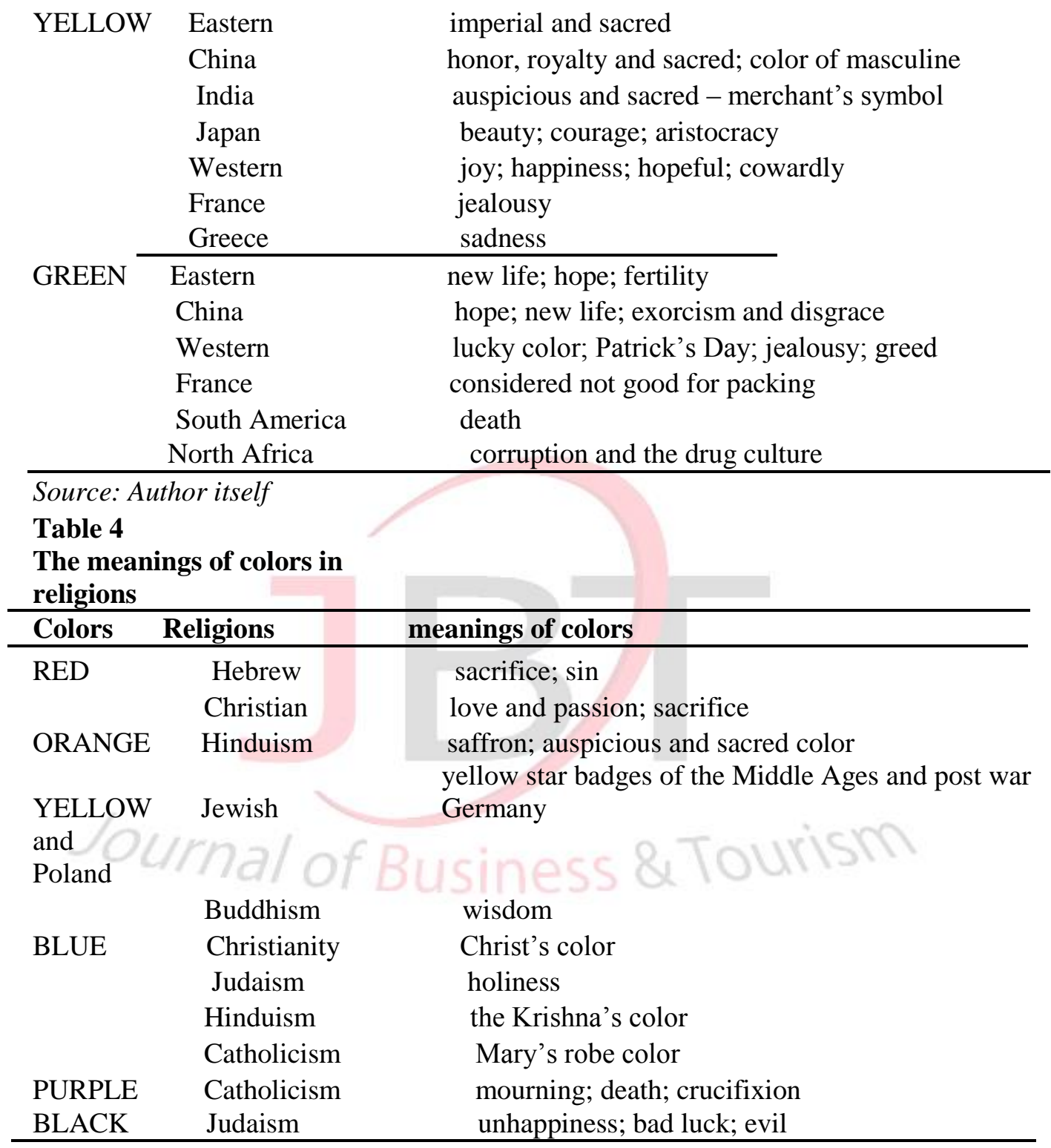

Source: Nezhad \& Kavehnezhad, 2013 